\title{
Comparison of COVID-19 Infection in Children During the First and Second Wave
}

\author{
Sriram Krishnamurthy ${ }^{1}\left[\right.$ D $\cdot$ Sitanshu Sekhar $\operatorname{Kar}^{2} \cdot$ Rahul Dhodapkar $^{3} \cdot$ Narayanan Parameswaran $^{1}$
}

Received: 25 July 2021 / Accepted: 24 November 2021/Published online: 19 February 2022

(c) Dr. K C Chaudhuri Foundation 2022

\begin{abstract}
Concerns have been raised in the media that 'the third wave' will severely affect children. Here, an experience of SARSCoV-2 infection in children is reported. Of the 8,626 SARS-CoV-2 RT-PCR tests performed in children (0-17 y) from March 2020 to July 2021 at the authors' institute, $1470(17 \%)$ were positive, [711/4821 (14.7\%) during the first wave (July 2020 to January 2021), and 759/3583 (21.2\%) during the second wave (February 2021 to July 2021)]. The children in both waves were similar in presentation ( $74.1 \%$ mildly symptomatic versus $80.2 \%$ mildly symptomatic; rest asymptomatic). None of them had COVID pneumonia. Five children died (0.3\%), all of a serious primary non-COVID disease. Seventy-three cases of MIS-C during August 2020 to July 2021, with low mortality (2.7\%) were also identified. The similarity in COVID-19 infection in children between the first and the second waves seems to suggest that the likelihood of the 'third wave' hitting children hard is low.
\end{abstract}

Keywords SARS-CoV-2 infection $\cdot$ Children $\cdot$ MIS-C $\cdot$ Third wave $\cdot$ COVID

\section{Introduction}

Since its first case of SARS-CoV-2 infection on January 30, 2020, India has reported over 33 million cases and more than 450,000 deaths. The first wave of SARS-CoV-2 infection was during March to September 2020, and there was a second wave during February to May 2021 [1, 2]. It is being predicted that the country will have a third wave by the end of 2021 [1]. Concerns have been raised that the third wave will predominantly affect children who are unvaccinated [3]. In this regard, the authors share their experience of SARSCoV-2 infection in children.

Sriram Krishnamurthy

drsriramk@yahoo.com

1 Department of Pediatrics, Jawaharlal Institute of Postgraduate Medical Education and Research (JIPMER), Pondicherry 605006, India

2 Department of Preventive and Social Medicine, Jawaharlal Institute of Postgraduate Medical Education and Research (JIPMER), Pondicherry, India

3 Department of Microbiology, Jawaharlal Institute of Postgraduate Medical Education and Research (JIPMER), Pondicherry, India

\section{Methods}

Data from several sources from March 2020 till July 2021 were analyzed: Online hospital information system, the SARS-CoV-2 testing records from the authors' Virology Laboratory online data; hospital records and discharge summaries for data on pediatric COVID infection and Multisystem inflammatory syndrome in children (MIS-C) in the 0-17 y age-group. The Institute Ethics Committee (IEC) granted exemption from review for this work.

\section{Results}

Of the 8,626 SARS-CoV-2 RT-PCR tests performed in children (0-17 y) from March 2020 to July 2021, 1470 (17\%) were positive, including 711/4821 (14.7\%) during the first wave (July 2020 to January 2021), and 759/3583 (21.2\%) children during the second wave (February 2021 to July 2021) (Table 1). Of these 1470 children [ages $3 \mathrm{~d}$ to $17 \mathrm{y} ; 790$ (53.7\%) boys], 731 (49.7\%) were managed at home, while 739 (50.3\%; 417 in the first wave and 322 in the second wave) were admitted for a non-COVID illness (620/739) or since parent(s) were admitted for COVID-19 (119/739). The patients in both the waves were similar in age distribution [median (IQR) 9 $(3,14)$ versus $8(2,13)$ y], gender $(55.3 \%$ males versus $52.9 \%$ 
Table 1 COVID-19 testing details among the pediatric age group at the authors' institute

\begin{tabular}{lll}
\hline & $\begin{array}{l}\text { First wave (March } \\
\text { 2020-Jan 2021) }\end{array}$ & $\begin{array}{l}\text { Second wave } \\
\text { (Feb 2021-July } \\
\text { 2021) }\end{array}$ \\
\hline $\begin{array}{l}\text { Total tested samples } \\
\begin{array}{l}\text { SARS-CoV-2 RT-PCR Posi- } \\
\text { tive }\end{array}\end{array}$ & 4821 & 3583 \\
Positivity rate* & 14.7 & 759 \\
\hline
\end{tabular}

* Positivity rate $=$ SARS-CoV-2 Positive/Total tested samples (excluding inappropriate samples, insufficient samples, double samples); 124 from tests from $1^{\text {st }}$ wave and 97 from $2^{\text {nd }}$ wave were excluded for this calculation

males) and presentation (mildly symptomatic $74.1 \%$ versus 80.2\%). None of the children had COVID pneumonia. Fifteen children had diarrhea (without dehydration). None had central nervous system manifestations. Overall, 5 children died $(0.3 \%)$, all of a serious primary non-COVID disease (one each with end-stage renal disease; acute lymphoblastic leukemia and tumor lysis syndrome; GM2 gangliosidosis and status epilepticus; toxic shock syndrome; and end-stage renal disease with uremic encephalopathy). These pediatric deaths formed only $0.5 \%$ of all 1053 deaths among those with SARS-CoV-2 infection at the authors' institute. Out of the 1470 children in this report, 89 were neonates. Their ages ranged from 3 to 28 $\mathrm{d}$, respectively. Five of them had low grade fever, while 10 had mild cough. The rest were asymptomatic. None of these had respiratory distress or required oxygen. There were no neonatal deaths.

Seventy-three cases of MIS-C [median (range) 4.5 y (0.2, 14); 63\% males] during August 2020 to July 2021, including $8(10.9 \%)$ who were positive for SARS-CoV-2 RNA were identified. Though these children had significant illness including myocardial dysfunction [40 (54.8\%)], coronary artery aneurysms [29 (39.7\%)], oxygen requirement [10 (13.7\%)], mechanical ventilation [7 (9.6\%)] and inotropes [22 (30.1\%)], the mortality was low $(2 / 73 ; 2.7 \%)$. Those with Kawasaki phenotype [33 (45.2\%)] required intravenous immunoglobulin, the remaining required methylprednisolone. Both the children who died of MIS-C had arrived late, with refractory shock and endotracheal intubation. Out of the 73 cases of MIS-C, 43 were from Puducherry, and the rest from other states.

\section{Discussion}

During this pandemic, children have consistently had milder clinical course worldwide [4-7]. In India too, there has been no change in the proportion of confirmed COVID19 patients aged $<10 \mathrm{y}$ and $10-20 \mathrm{y}$ [8], and the mortality rate in both waves is similar [9]. However, since the second wave was larger, the absolute number of children with COVID-19 was larger. Overall, during both the first wave and the second waves in India, reported outcomes in children were good. Children with COVID-19 infection might be having better outcomes due to under-development of the angiotensin-converting enzyme 2 ; and better inflammatory response against the virus [10].

The cases of MIS-C at the authors' institution represent a referral bias. Unpublished data from their institution indicate that anti-SARS-CoV-2 antibodies were detected in 70\%-80\% of children in Puducherry (personal communication).

\section{Conclusion}

Though SARS-CoV-2 infection is common in children, disease is usually mild, with very low mortality; this was true for both the first wave caused by the ancestral strain as well as the second wave caused by the delta variant. A large proportion of children are already seropositive through natural infection. It is, therefore, believed that there is unlikely to be a surge in clinically significant disease in children during 'the third wave' in spite of vaccination being unavailable for routine usage in children currently. MIS-C, a special phenotype in children, can be optimally managed, if recognized early. Considering the multiple deleterious effects of closure of schools, a calibrated approach towards re-opening of schools should be prioritized.

Acknowledgements The authors thank Dr Rakesh Aggarwal, Director, JIPMER, Puducherry for his valuable suggestions and editing of the manuscript; and Dr Palanivel C, Additional Professor, Department of Preventive and Social Medicine for inputs regarding seroprevalence from Puducherry.

Authors' Contributions SK and NP were involved in management of the patients. SK and SSK collected the data, reviewed the literature, and drafted the first version of the manuscript. RD interpreted the microbiological tests. All authors contributed to drafting of the manuscript and approved the final version of the manuscript. SK will act as the guarantor for this paper.

\section{Declarations}

Conflict of Interest None.

\section{References}

1. Kavitha C, Gowrisankar A, Banerjee S. The second and third waves in India: when will the pandemic be culminated? Eur Phys J Plus. 2021;136:596.

2. Mandal S, Arinaminpathy N, Bhargava B, Panda S. Plausibility of a third wave of COVID-19 in India: A mathematical modelling based analysis. Indian J Med Res. 2021;153:522-32. 
3. Kumar K. Will there be a third wave of the pandemic affecting children? The Indian Express. 2021. Available at: https://indianexpress. com/article/parenting/health-fitness/will-there-be-a-third-wave-ofthe-pandemic-affecting-children-7384613/. Accessed on 21 July 2021.

4. Götzinger F, Santiago-García B, Noguera-Julián A, et al; ptbnet COVID-19 study group. COVID-19 in children and adolescents in Europe: a multinational, multicentre cohort study. Lancet Child Adolesc Health. 2020;4:653-61.

5. Mehta NS, Mytton OT, Mullins EWS, et al. SARS-CoV-2 (COVID-19): what do we know about children? a systematic review. Clin Infect Dis. 2020;7:2469-79.

6. Badal S, Thapa Bajgain K, Badal S, Thapa R, Bajgain BB, Santana MJ. Prevalence, clinical characteristics, and outcomes of pediatric COVID-19: A systematic review and meta-analysis. J Clin Virol. 2021;135:104715.

7. Bhuiyan MU, Stiboy E, Hassan MZ, et al. Epidemiology of COVID-19 infection in young children under five years: A systematic review and meta-analysis. Vaccine. 2021;39:667-77.
8. The Economic Times. Proportion of youths, children infected in both waves same. Available at: https://economictimes.indiatimes. com/news/india/proportion-of-youths-children-infected-in-bothwaves-same/articleshow/83554071.cms?from $=$ mdr. Accessed on 9 Feb 2022.

9. Kumar G, Mukherjee A, Sharma RK, et al. National clinical registry for COVID-19 team. clinical profile of hospitalized COVID-19 patients in first \& second wave of the pandemic: Insights from an Indian registry based observational study. Indian J Med Res. 2021;153:619-28.

10. Mantovani A, Rinaldi E, Zusi C, Beatrice G, Saccomani MD, Dalbeni A. Coronavirus disease 2019 (COVID-19) in children and/or adolescents: a meta-analysis. Pediatr Res. 2021;89:733-7.

Publisher's Note Springer Nature remains neutral with regard to jurisdictional claims in published maps and institutional affiliations. 